\title{
Regime Shift Analysis and Numerical Simulation for Effective Ecosystem Management
}

\author{
Hock Lye Koh, Wai Kiat Tan, and Su Yean Teh
}

\begin{abstract}
Ecosystems are constantly subject to shifts among multiple locally stable and unstable states. Such regime shifts or bifurcations are fascinating ecological phenomena, involving multiple causes and many variables that change at different spatial-temporal scales, potentially altering the direction of feedbacks. They are crucial for effective ecosystem management because regime shifts may impair valuable ecosystem services provided by nature and because recovery of desired states may be difficult and costly. Lakes may undergo regime shifts between two alternative steady states, oligotrophic or eutrophic, due to the strong interaction between exogenous phosphorus $(P)$ input and endogenous interaction between water and sediment $P$. Many lakes exhibit either a desirable oligotrophic clear-water state with abundant macrophytes and low chlorophyll concentrations, or an undesirable eutrophic turbid condition with high chlorophyll concentrations and sparse macrophytes. A regime shift from a clear-water oligotrophic state to a turbid eutrophic condition may occur in response to a combination of increased exogenous nutrient loading and a strong feedback involving $P$ release from the sediments. This paper presents water and sediment quality data for a small shallow stagnant lake in Selangor Malaysia indicating progressive deterioration of water quality arising from intensification of eutrophication due to accumulated nutrient loading from a relatively large human settlement over three decades. It then provides numerical simulations and analytical synthesis for explaining and predicting the prognosis of lake eutrophication regime shifts. The paper concludes with a practical and sustainable remediation measure for rehabilitating lake eutrophication.
\end{abstract}

Index Terms-Algae, eutrophication, phosphorus, regime shift.

\section{INTRODUCTION}

Ecosystems, particularly aquatic ecosystems, are constantly subject to shifts among multiple locally stable and unstable states [1]. Such regime shifts are fascinating ecological phenomena, involving multiple causes and many variables that change at different spatial-temporal scales, potentially altering the direction of feedbacks [2], [3]. Induced by increasing human disturbance and climate change, significant regime shifts in the ecosystem structures and

Manuscript received February 5, 2018; revised July 3, 2018. This work was supported in part by FRGS grant \#203/PMATHS/6711569 awarded to TSY and the Sunway University Internal Research Grant Scheme INT-2018-SMS-05 awarded to TWK

H. L. Koh is with the Jeffrey Sachs Center on Sustainable Development, Sunway University, Bandar Sunway, 47500 Subang Jaya, Selangor, Malaysia (e-mail: hocklyek@sunway.edu.my).

W. K. Tan is with the School of Mathematical Sciences, Sunway University, Bandar Sunway, 47500 Subang Jaya, Selangor, Malaysia (e-mail waikiatt@sunway.edu.my).

S. Y. Teh is with the School of Mathematical Sciences, Universiti Sains Malaysia, 11800 USM, Pulau Pinang, Malaysia (e-mail: syteh@usm.my). functions in many lakes have been observed in recent decades worldwide. For example, a small stagnant lake known as Sunway Lagoon in the state of Selangor, Malaysia has shown signs of regime shift to eutrophication. This paper is dedicated to a concerted effort to rehabilitate the lake back to the desired clear-water oligotrophic condition. To identify the characteristics of regime shifts in lakes, to explore early warning signals prior to regime shifts and to provide effective remediation are critical issues in lake conservation and management. However, identifying and predicting regime shifts in lakes is still a formidable task. In this paper, we focus on lake eutrophication problems and the associated regime shifts between two alternative steady states, the oligotrophic and eutrophic states. We begin in this section with a brief review of eutrophication and the associated regime shifts between oligotrophic and eutrophic states in two largest shallow lakes in China, namely Lakes Dianchi and Chaohu, to lay the foundation for further deliberation. This review will provide valuable insights and critically needed data that can be used for model simulations later.

Firstly, Lake Dianchi, covering a surface area of $330 \mathrm{~km}^{2}$, with a mean depth of $4.4 \mathrm{~m}$, and watershed area of $2920 \mathrm{~km}^{2}$, is a plateau lake located in Kunming City, the capital of Yunnan province. After receiving 90\% of Kunming City's wastewater over the decades, Lake Dianchi is seriously contaminated by eutrophication, where cyanobacterial blooms occur annually over the whole lake, impairing critical ecosystem services such as fresh water supply and ecotourism [4]. The lake water quality is rated as Grade V, the worst grade in China [5]. For Dianchi lake, most biomasses and trophic flows are primarily concentrated at the lower three trophic levels (TLs) out of six. The primary producer level (TLI) consists mainly of detritus and phytoplankton; while TLII consists mainly of the groups of zooplankton and zoo-benthos, and filter-feeding fish (silver carp and bighead carp) and herbivorous fish. The biomass of shrimps at TLIII in Lake Dianchi is huge $\left(29.85 \mathrm{t} \cdot \mathrm{km}^{-2}\right)$, suggesting the importance of lake ecosystem services provided. Shrimps occupy more than $67 \%$ of the total fishery; with the remaining consisting of zooplanktivore fish. The mean trophic level of fish catch is estimated to be 3.06 , which is close to the value for TLIII. It is slightly higher than the value (2.92) for Lake Taihu [6], [7], and close to the value (3.07) for Northern and Central Adriatic Sea [8]. About $77.5 \%$ of the trophic flows from TLI to TLII originate from the detritus, whereas high proportions of under-utilized zooplankton biomass returned to the detritus because of low transfer efficiencies $(2.9 \%)$ in TLII. Positive feedback within the lower TLs locks the nutrients and promotes the inflation of biomass in plankton communities. Dianchi, Chaohu and Taihu Lakes are clearly thought to be a bottom-up control ecosystem [9] 
Chlorophyll-a (Chl-a) concentration started in 1980 to 1985 at about $10 \mu \mathrm{g} \mathrm{Chl} \cdot \mathrm{L}^{-1}$ (mesotrophic), but gradually increased to $25 \mu \mathrm{g} \mathrm{Chl} \cdot \mathrm{L}^{-1}$ (eutrophic) by 1995 . However, within the next 15 years, the levels increased exponentially to $160 \mu \mathrm{g} \mathrm{Chl} \cdot \mathrm{L}^{-1}$ (hypertrophic) by 2000 and maintained at $128.21 \pm 35.32 \mu \mathrm{g}$ $\mathrm{Chl} \cdot \mathrm{L}^{-1}$ (hypertrophic) from 2009 to 2010 . Total phosphorus (TP) varied between 0.2 to $0.4 \mathrm{mg} \cdot \mathrm{L}^{-1}$; total nitrogen $(\mathrm{TN})$ varied between 2.0 to $3.5 \mathrm{mg} \cdot \mathrm{L}^{-1}$, while Secchi depth varied between 13 to $36 \mathrm{~cm}$ [9]. Frequent episodes of Microcystis blooms are found in all three large shallow lakes: Lakes Dianchi, Chaohu and Taihu. At these three lakes, the China government has invested, and will continue to invest, billions to prevent the occurrence of these toxic algae blooms and to sustain reliable portable water supplies for the surrounding cities totally more than 20 million people. Re-establishing aquatic macrophytes in lakeside littoral zones and introducing artificially cultured filter-feeding carp (bighead and silver carp to graze on phytoplankton), successfully decreased the nutrient concentration to some extent [10]. Recent research has revealed the importance of internal nutrient dynamics that trigger and maintain regime shifts in lake eutrophication [11]. This paper is motivated by the wish to convey valuable insights on lake eutrophication remediation and management, focusing on the role of regime shifts, using the Sunway Lagoon as a working example.

Secondly, Lake Chaohu is the fifth largest lake in China, with a surface area of about $780 \mathrm{~km}^{2}$, and mean depth of 3.06 m. Lake Chaohu provides important ecological services, including portable water supply, for the 7.6 million people living in the basin. The ecosystem of Lake Chaohu shifted from the clear to turbid state during late 1970s. The lake began to face serious eutrophication since the 1980s. TP loading amounted to $1050 \mathrm{t} \cdot \mathrm{y}^{-1}$ in the late 1980s [12] and increased to $1550 \mathrm{t} \cdot \mathrm{y}^{-1}$ during 2002 to 2010 . About $85 \%$ of the $\mathrm{TN}$ and $77 \%$ of the TP loading originate from non-point sources. These loadings are higher than expected, thus suggesting the un-specified nutrient flux from the soil in the basin. Analysis by the DyN model indicates that the TP loading thresholds that would shift the clear to the turbid state is $631.8 \pm 290.16 \mathrm{t} \cdot \mathrm{y}^{-1}$, which is equivalent to $0.73 \mu \mathrm{g} \cdot \mathrm{L}^{-1} \cdot \mathrm{d}^{-1}$ of TP [13]. This external TP loading threshold will be used as a benchmark in simulations for Sunway Lagoon in this paper. Further, eutrophication of Lake Chaohu is more likely to be reversible $(74.12 \%)$ than hysteretic $(25.53 \%)$, based upon DyN simulation and analysis. To shift from the current turbid eutrophic state back to the clear water oligotrophic state, the current TP loading must be reduced by two-third [13]. However, in real practice the reduction of non-point sources is very difficult and costly. Hence, additional methods beyond nutrient input reduction, such as water level regulation, should be considered for lake restoration.

Research shows a persistent correlation between the development of cyanobacterial blooms and the increase of soluble reactive phosphorus (SRP) in the lake water of Dianchi [5]. Cyanobacterial blooms are a driving force for phosphorus (P) mobility and exchange among sediments, water and cyanobacteria. The $\mathrm{P}$ in the sediments represents a significant supply for the growth of cyanobacteria. Although much effort has been made to reduce the external loading of $\mathrm{P}$ in lakes, $\mathrm{P}$ released from the sediments may act in such an intense and persistent manner that it prevents the improvement of water quality [14]. Algal blooms have positive feedback on the release of $\mathrm{P}$ from sediment. Research in Lake Donghu shows that dissolved $\mathrm{P}$ released from sediment back to lake water could be enhanced by algal blooms [15]. Generally, P is believed to be a limiting factor for cyanobacterial growth. The Chl-a and SRP in the overlying water are significantly related. Inorganic P (IP) is the main $\mathrm{P}$ fraction, with IP mainly consisting of $\mathrm{NaOH}-\mathrm{P}$ in the heavily eutrophic sediment. IP and $\mathrm{NaOH}-\mathrm{P}$ are relatively easier to migrate out of sediment back to the water. In another independent study, most of the $\mathrm{P}$ in the sediment consists of IP [16]. The death and decaying cyanobacteria would promote the release of $\mathrm{P}$ from sediments back into the water body, and the released $\mathrm{P}$ would in turn help new cyanobacteria growth. The proliferation of cyanobacteria drives sediment $\mathrm{P}$ release, sustaining a vicious cycle. The development of cyanobacterial blooms caused an increase in the $\mathrm{pH}$ from 8 to 12 . It has been demonstrated that an increase in $\mathrm{pH}$ may increase $\mathrm{P}$ release from sediments.

\section{LAKE EUTROPHICATION AND REGIME SHIFT}

Lakes, small and large, provide essential services to ecosystems, wildlife and human. However, many lakes, such as the Sunway Lagoon, are subject to environmental stresses due to nutrient loading from the surrounding neighborhood, leading to eutrophication and to a potential loss of critical ecosystem services. The eutrophication of lakes is largely a consequence of human-induced nutrient enrichment and is hence frequently referred to as cultural eutrophication. To distinguish it from other more severe forms of pollution, eutrophication is legally defined as "the enrichment of water by nutrients causing an accelerated growth of algae and other forms of plant life to produce an undesirable disturbance to the aquatic environment". The natural progression of eutrophication symptoms from oligotrophic state generally begins with an initial surge in phytoplankton biomass and macro-algal blooms, followed by more severe impacts such as a loss of submerged macrophytes, depleted oxygen levels, proliferations of harmful and toxic algal blooms, fish-kills, and the formation of "dead zones" [17], [18]. A lake may be classified into four categories as follows: (1) oligotrophic (Good), (2) mesotrophic (Fair), (3) eutrophic (Poor) and (4) hypertrophic (Very Poor) [19]. However, we will consider only two steady states, namely oligotrophic and eutrophic states, as the other two states are part of the continuum. Lakes may undergo regime shift between two alternative steady states, oligotrophic and eutrophic, due to the strong interaction between exogenous $\mathrm{P}$ input and endogenous interaction between water and sediment P. Mean depth, sediment $\mathrm{P}$ storage and temperature strongly influence the susceptibility of lakes to regime shifts; while water surface area plays an insignificant role [20]. Many other factors, including lake morphometry, sediment quality and thickness, and dominance of macrophytes also play a role, making the shift quite variable and difficult to predict before its occurrence. Undesirable shift from a clear-water state to a turbid condition will have adverse ecosystem impacts and 
may reduce important ecosystem services. Restoration to oligotrophic state after the shifts to eutrophic states is costly or may be impossible in certain situations. Hence, precise evaluation of the potential occurrence of regime shifts and the severity of the impacts is needed for good lake management. Abundant macrophyte may prevent $\mathrm{P}$ recycling from sediments and reduce the susceptibility of shallow lakes to regime shift. However, some lakes, such as the Sunway Lagoon (depth of $8 \mathrm{~m}$ and surface area of 5 acres), may be too deep relative to the surface area to be protected by macrophytes in their limited littoral zones. Global warming may enhance eutrophication, and render lake restoration costlier and less successful due to increased internal $\mathrm{P}$ recycling from the sediment. Shallow lakes are most susceptible to regime shifts and are least restorable if the areas are large. An example is the Harapan Lake (located in the USM campus at Penang, Malaysia), with a depth of $1.5 \mathrm{~m}$ and a surface area of 1.5 acres. Persistent and frequent hypertrophic condition occurred annually, with Chl-a concentration reaching $330 \mu \mathrm{g} \mathrm{Chl} \cdot \mathrm{L}^{-1}$ occasionally [21]. The three largest lakes in China mentioned earlier are all large and shallow, rendering the restoration costly and difficult. The interplay of multiple abiotic, physical, chemical, and biotic mechanisms in regime shifts observed in lakes may also arise in regime shifts of other types of ecosystems [20], such as mangroves and grasslands, although the underlying causes are quite different. Insights gained from this research may have the potential of being applied to other ecosystems. The IP in lake bottom is bound to iron in the sediments under oxygenated conditions but is released back to the water column when the sediment surface is deoxygenated. This is a main driver in regime shifts in shallow lakes, regardless of their surface areas. One of the main causes of oxygen depletion near the sediment layer is the decomposition of sinking phytoplankton, the density of which is related to lake trophic status. High phytoplankton concentrations induced by eutrophication lead to more sedimentation that promotes bacterial respiration and anoxia. Anoxia, in turn, leads to additional $\mathrm{P}$ release from the sediments, triggering and sustaining a vicious cycle of positive feedback mechanism that promote regime shift to eutrophication.

The commonly used sigmoid model of $\mathrm{P}$ internal recycling between water column and sediments contains a critical parameter (the half-saturation constant) and the slope parameter that are difficult to estimate for most lakes [22] and are probably a function of lake morphometry and water temperature [23]. It is preferable to have a model with parameters that are stable for a wide variety of limnological conditions, and that are readily estimated from available data [20]. Many factors could cause great variability among lakes in determining the thresholds for eutrophication and regime shifts. Mean depth and temperature are critical in determining the direction and strength of regime shift arising from eutrophication. The effects of macrophytes are closely associated with mean depth and are stronger in shallower lakes due to more littoral plants. However, there is little consensus within the literature concerning the precise mechanism how macrophytes affect nutrient recycling. Nevertheless, macrophyte cover is expected to decrease the recycling of $\mathrm{P}$ by reducing sediment resuspension and can help control algal blooms by providing refuge for zooplankton against fish predation, thereby promoting zooplankton grazing of phytoplankton [24].

\section{REGIME SHIFT MODEL}

Over the last decades there has been an increasing focus on the risks posed by high consequence thresholds or "tipping point" responses across a range of coupled environmental economic systems, particularly of hydrological systems linking lakes and watersheds [25]. When the control parameters (e.g. P, algae) reach a critical threshold, the current system regime (e.g. oligotrophic) abruptly shifts to an alternate regime (e.g. eutrophic)—a process known as bifurcation-tipping [26]. As noted earlier, the abrupt regime shift (bifurcation tipping) from an oligotrophic to a eutrophic regime can be rapid once the concentration of $\mathrm{P}$ (or algae) in a lake reaches a critical threshold, enhanced by sediment inputs. The tight coupling between sediment, water and cyanobacteria mediated via high $\mathrm{pH}$ and low dissolved oxygen (DO) at or near the sediments render the response to ecological system dynamics of shallow lakes highly nonlinear. High nonlinearity offers ample opportunity for sudden and abrupt regime shift requiring costly remediation action if the shift is not detected early [5]. It is therefore crucial to develop methodology, based upon monitoring and modeling, to detect such abrupt shift [27] and to take effective mitigation measures for preventing the occurrence of such abrupt shift to more severe form of eutrophication.

In this section, a minimalist two-component model that describes the relationship between $\mathrm{P}$ and algae concentration in lakes is used to investigate the conditions that govern regime shifts between oligotrophic and eutrophic states for Sunway Lagoon. The model consists of two dynamic variables, namely concentrations of chlorophyll-a (Chl-a, as a surrogate for algae) $A\left(\mu \mathrm{g} \mathrm{Chl} \cdot \mathrm{L}^{-1}\right)$ and phosphorus $P(\mu \mathrm{g}$ $\left.\mathrm{P} \cdot \mathrm{L}^{-1}\right)$, as follows [20]:

$$
\begin{aligned}
& \frac{d A}{d t}=b P A-\left(g+\frac{s}{z_{e}}+h\right) A, \\
& \frac{d P}{d t}=l+r+e g A-b A P-h P .
\end{aligned}
$$

TABLE I: DEFINITION AND UNITS OF PARAMETERS, SUNWAY LAGOON

\begin{tabular}{llcc}
\hline \hline Parameters & \multicolumn{1}{c}{ Definition } & Unit & Value \\
\hline$b$ & Algal growth rate & $\mathrm{L} \cdot \mu \mathrm{g} \mathrm{P} \mathrm{P}^{-1} \cdot \mathrm{d}^{-1}$ & 0.9000 \\
$g$ & per unit $P$ & $\mathrm{~d}^{-1}$ & 0.0300 \\
$s$ & Zooplankton grazing rate & $\mathrm{m} \cdot \mathrm{d}^{-1}$ & 0.0850 \\
$z_{e}$ & Algal sinking rate & $\mathrm{m}$ & 7.0000 \\
$h$ & Thickness of epilimnion & $\mathrm{d}^{-1}$ & 0.0006 \\
$l$ & Flushing rate & $\mu \mathrm{g} \mathrm{P} \cdot \mathrm{L}^{-1} \cdot \mathrm{d}^{-1}$ & 0.02 to 0.50 \\
$r$ & External $P$ loading rate & $\mu \mathrm{g} \mathrm{P} \cdot \mathrm{L}^{-1} \cdot \mathrm{d}^{-1}$ & computed \\
& Internal $P$ sediment & $\mu \mathrm{g} \mathrm{P} / \mu \mathrm{g} \mathrm{chl}$ & 0.6500 \\
\hline \hline
\end{tabular}

The definitions and units of the parameters, to be used for Sunway Lagoon regime shift analysis, are listed in Table I. As may be observed in (1), Chl-a concentration increases at a rate 
$b$ due to algae growth and decreases at a rate $g$, due to algae grazing by zooplankton coupled with algae sinking at a rate $s / z_{e}$ and flushing rate $h$. As observed in (2), P concentration increases by external loading $l$, internal sediment recycling $r$ and excretion from zooplankton $e g A$. On the other hand, $\mathrm{P}$ concentration decreases at the rates of $b$ due to algae uptake and $h$ due to flushing. Note that $r$ is computed as follows:

$$
r=R / z_{e}
$$

where $R\left(\mathrm{mg} \cdot \mathrm{m}^{-2} \cdot \mathrm{d}^{-1}\right)$ is the areal $P$ recycling rate from the sediments into the water column, while $z_{e}$ is the epilimnion depth. Note that, no unit conversion is required in (3) as 1 $\mu \mathrm{g} \cdot \mathrm{L}^{-1}$ is equal to $1 \mathrm{mg} \cdot \mathrm{m}^{-3}$. Based on Charlton (1980) [28] model, $R$ can be computed as follows:

$$
R=\frac{R_{\max }}{t_{s}} \times\left\lfloor t_{s}-\frac{D O \times\left(50+z_{h}\right)}{3.8 \times \frac{1.15 A^{1.33}}{9+1.15 A^{1.33}} \times 2^{\frac{T-4}{10}}+0.12}\right\rfloor,
$$

where $R_{\text {max }}\left(14 \mathrm{mg} \cdot \mathrm{m}^{-2} \cdot \mathrm{d}^{-1}\right)$ is the maximum areal P recycling rate, $t_{s}(60$ days $)$ is the stratified period, $D O\left(7.97 \mathrm{mg} \cdot \mathrm{L}^{-1}\right)$ is the saturated oxygen concentration corresponding to the temperature $T\left(27^{\circ} \mathrm{C}\right)$ and $z_{h}(1 \mathrm{~m})$ is the hypolimnion depth.

To find the fixed points for (1) and (2), set (1) equal to 0 :

$$
b P A-\left(g+\frac{s}{z_{e}}+h\right) A=0 ; A\left\lfloor b P-\left(g+\frac{s}{z_{e}}+h\right)\right\rfloor=0
$$

yielding two cases of

$$
\text { (i) } A=0 \quad \text { and } \quad \text { (ii) } P=\frac{g+\frac{s}{z_{e}}+h}{b}=\frac{X}{b} \text {, }
$$

where $X=g+s / z_{e}+h$. For case (i), set (2) equal to 0 to find the equilibrium of $P$ :

$$
l+r+-h P=0 ; P=\frac{l+r}{h},
$$

yielding one fixed point of $\left(0, \frac{l+r}{h}\right)$. For case (ii), again set (2) equal to 0 to find the equilibrium of $A$ :

$$
l+r+e g A-b A \frac{X}{b}-h \frac{X}{b}=0 ; A=\frac{h \frac{X}{b}-(l+r)}{e g-X},
$$

yielding another fixed point of $\left(\frac{h \frac{X}{b}-(l+r)}{e g-X}, \frac{1}{b} X\right)$.

The regime shift model discussed above will now be utilized to analyze eutrophication and regime shifts in a small urban eutrophicated lake known as the Sunway Lagoon, located in the state of Selangor, Malaysia. The goal is to ensure that Sunway Lagoon lake water quality will revert back to oligotrophic state by the implementation of effective remediation measures, based upon field data and regime shift model simulations and theoretical synthesis.

\section{Sunway Lagoon Lake Data}

Located within a highly populated urban city of about 700 acres, Sunway Lagoon is a small man-made lake with a surface area of 5 acres and depth of about $8 \mathrm{~m}$. The lake is located below sea level with no outflow. The lake water is, however, periodically pumped off the lake after a heavy rain. It is therefore subject to accumulation of nutrients and other pollutants in the sediments due to inflows from the city surrounding the lake, in the form of non-point sources, consisting of surface runoffs and groundwater inflows that contain high nutrients. The lake is currently (2017) classified as Class III Malaysia Water Quality Criteria [29]. The accumulation of nutrients in the sediment has been significant over the duration of 17 years from 1993 to 2010. A water quality survey was conducted on 24 to 25 June 2010. Water samples were collected at 10 evenly separated locations at three water depths: surface $(0.5 \mathrm{~m})$, mid-depth $(3.5 \mathrm{~m})$ and lake bottom $(7.5 \mathrm{~m})$. Sediments were collected at 10 different locations in the bottom sediment. Overall the water quality was classified as Class II B (2010), with surface water DO generally falling below $5 \mathrm{mg} \cdot \mathrm{L}^{-1}$, indicating DO stressed environment detrimental to aquatic lives including fish. Temperature was between $27^{\circ} \mathrm{C}$ to $31{ }^{\circ} \mathrm{C}$, while $\mathrm{pH}$ was around 7. Concentration of DO measured at $1.26 \mathrm{mg} \cdot \mathrm{L}^{-1}$ near the bottom, $1.59 \mathrm{mg} \cdot \mathrm{L}^{-1}$ at mid-depth and $4.74 \mathrm{mg} \cdot \mathrm{L}^{-1}$ at the surface, indicating a DO deprived water environment. Concentration of Chl-a varied between 5 and $15 \mu \mathrm{g} \mathrm{Chl} \cdot \mathrm{L}^{-1}$, suggesting a mesotrophic condition. With TN concentration varying between 0.2 and $0.9 \mathrm{mg} \cdot \mathrm{L}^{-1}$ and $\mathrm{TP}$ between 0.1 and $0.4 \mathrm{mg} \cdot \mathrm{L}^{-1}$, the water was regarded as nutrients rich, capable of supporting vibrant algae growth to a potentially eutrophic or hypertrophic level over time. The sediments were tested for 17 heavy metals at 10 different locations. The heavy metal concentrations were generally low except for iron, aluminum and manganese. Further, the sediment concentrations for $\mathrm{P}$ and $\mathrm{N}$ are high, reflecting a eutrophic condition. Table 2

\begin{tabular}{|c|c|c|c|}
\hline Component & Range of value & Level & Comment \\
\hline $\mathrm{TP}\left(\mathrm{mg} \cdot \mathrm{kg}^{-1}\right)$ & 22 to 81 & High & Un-desirable \\
\hline $\mathrm{TN}\left(\mathrm{mg} \cdot \mathrm{kg}^{-1}\right)$ & 68 to 246 & High & Un-desirable \\
\hline TOC $\left(\% \mathrm{w} \cdot \mathrm{w}^{-1}\right)$ & 0.4 to 1.5 & High & Un-desirable \\
\hline Iron $\left(\mathrm{mg} \cdot \mathrm{kg}^{-1}\right)$ & 5225 to 13190 & High & Un-desirable \\
\hline Aluminum $\left(\mathrm{mg} \cdot \mathrm{kg}^{-1}\right)$ & 8921 to 83890 & High & Un-desirable \\
\hline
\end{tabular}
provides concentrations of $\mathrm{TP}, \mathrm{TN}$, total organic carbon (TOC), iron and aluminum in the sediments sampled in June 2010 .

TABLE II: TP, TN, TOC, IRON AND ALUMINUM CONCENTRATIONS IN SEDIMENT, SUNWAY LAGOON, 2010 [29]

After the 2010 study, a water and sediment quality sampling was conducted again on 23 January 2017. Overall, the sampling results indicate eutrophic status. Further, the $\mathrm{N}$ 
concentration in the sediments sampled in January 2017 measuring $739 \mathrm{mg} \cdot \mathrm{kg}^{-1}$ (based upon an average of 3 sampling locations) has increased by $600 \%$ as compared to that in 2010 ( 68 to $246 \mathrm{mg} \cdot \mathrm{kg}^{-1}$ based upon 10 sampling locations). Water quality samples were collected at three depths of $0.5 \mathrm{~m}$ (surface), $3.5 \mathrm{~m}$ (mid-depth) and $7.5 \mathrm{~m}$ (bottom) below water surface. The sampling results indicate a water quality standard of Class III [29]. Therefore, there is an urgent need to rehabilitate Sunway Lagoon to a water quality status consistent with that required for a recreational tourist attraction. Seven aerators are currently in operation to supply additional oxygen from the lake bottom to support fish and other aquatic life and to increase DO levels. A summary of results for biochemical oxygen demand $\left(\mathrm{BOD}_{5}\right), \mathrm{DO}$ and Chl-a at these 3 water depths respectively is provided in Table 3. Averaged concentration of sediment TP, TN and TOC are given in Table IV.

TABLE III: WATER BOD, DO AND CHL-A CONCENTRATION, 2017[29]

\begin{tabular}{lccccc}
\hline \hline \multirow{2}{*}{ Component } & \multicolumn{3}{c}{ Depth $(\mathrm{m})$} & Level & Comment \\
\cline { 2 - 4 } & 0.5 & 3.5 & 8.0 & & \\
\hline BOD $\left(\mathrm{mg} \cdot \mathrm{L}^{-1}\right)$ & 3.8 & 7.7 & 5.7 & High & Un-desirable \\
DO $\left(\mathrm{mg} \cdot \mathrm{L}^{-1}\right)$ & 4.3 & 3.8 & 3.9 & High & Un-desirable \\
Chl-a $\left(\mu \mathrm{g} \cdot \mathrm{L}^{-1}\right)$ & 13.0 & 11.2 & 9.8 & High & Un-desirable \\
\hline \hline
\end{tabular}

TABLE IV: TP, TN AND TOC CONCENTRATIONS IN SEDIMENT, 2017 [29]

\begin{tabular}{lccc}
\hline \hline Component & Value & Level & Comment \\
\hline TP $\left(\mathrm{mg} \cdot \mathrm{kg}^{-1}\right)$ & 61.0 & High & Un-desirable \\
TN $\left(\mathrm{mg} \cdot \mathrm{kg}^{-1}\right)$ & 739.0 & High & Un-desirable \\
TOC $\left(\% \mathrm{w} \cdot \mathrm{w}^{-1}\right)$ & 0.5 & High & Un-desirable \\
\hline \hline
\end{tabular}

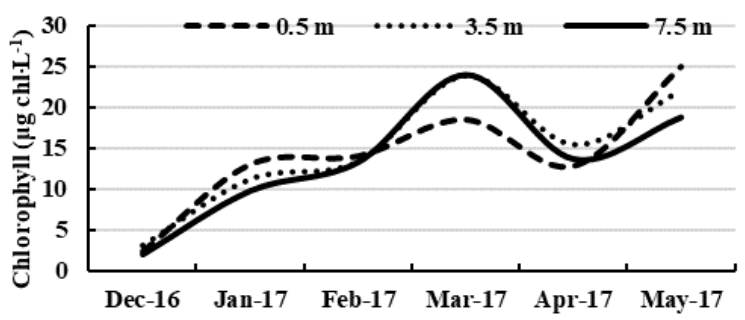

Fig. 1. Chl-a concentration in Sunway Lagoon, 2016 to 2017.

A series of six monthly water quality sampling at three depths $(0.5,3.5,7.5 \mathrm{~m}$ below water surface) was also conducted for six months from December 2016 to May 2017. Water quality parameters sampled include temperature, $\mathrm{pH}$, BOD, DO, ammoniacal nitrogen, nitrate nitrogen, $\mathrm{P}, \mathrm{Chl}-\mathrm{a}$, total coliform, and E. coli. Of concern is the high and increasing levels of Chl-a recorded during the six months of sampling, generally between 10 and $25 \mu \mathrm{g} \mathrm{Chl} \cdot \mathrm{L}^{-1}$, indicating a eutrophic lake condition. In general, an oligotrophic lake (clear water) should have Chl-a level below $2 \mu \mathrm{g} \mathrm{Chl} \cdot \mathrm{L}^{-1}$; while a mesotrophic lake (slightly turbid) should have Chl-a between 2 and $9 \mu \mathrm{g} \mathrm{Chl} \cdot \mathrm{L}^{-1}$. Level of Chl-a between 10 and 25 $\mu \mathrm{g} \mathrm{Chl} \cdot \mathrm{L}^{-1}$ is considered eutrophic and undesirable. Fig. 1 shows the trend of Chl-a during the six-month sampling duration, indicating a eutrophic lake. Nutrients can potentially be released from the sediment layers back into the water column if the aquatic conditions are suitable, for example if $\mathrm{pH}$ is above 8 or DO is depleted. High $\mathrm{pH}$ and low DO could be facilitated and maintained by cyanobacteria activity sustained by high $\mathrm{P}$ concentration. This phenomenon of self-reinforcing positive feedback loop can intensify algae growth towards a regime shift leading to hypertrophic condition, a major concern for Sunway Lagoon, as a tourist attraction.

\section{RESULTS}

The equilibrium $\mathrm{P}$ concentration in (1) and (2) is given by

$$
P^{*}=\frac{1}{b}\left(g+\frac{s}{z_{e}}+h\right),
$$

which is independent of $l$ and $r$. The equilibrium Chl-a concentration $\left(A^{*}\right)$ can be determined numerically when (2) changes sign by iterating $A$, from $0.0 \mu \mathrm{g} \mathrm{Chl} \cdot \mathrm{L}^{-1}$ to $60.0 \mu \mathrm{g}$ $\mathrm{Chl} \cdot \mathrm{L}^{-1}$, with an increment of $0.01 \mu \mathrm{g} \mathrm{Chl} \cdot \mathrm{L}^{-1}$. For a given external $\mathrm{P}$ loading rate $l$ value, this iteration can yield either one stable equilibrium or three equilibria. The TP external input for Chaohu is $0.73 \mu \mathrm{g} \mathrm{TP} \cdot \mathrm{L}^{-1} \cdot \mathrm{d}^{-1}$. For Sunway Lagoon simulations, the external $\mathrm{P}$ input used is IP, which is much less than TP. Further, Sunway Lagoon is less eutrophic than Chaohu; hence the IP input for Sunway Lagoon is chosen to vary between 0.01 to $0.10 \mu \mathrm{g} \mathrm{IP} \cdot \mathrm{L}^{-1} \cdot \mathrm{d}^{-1}$.
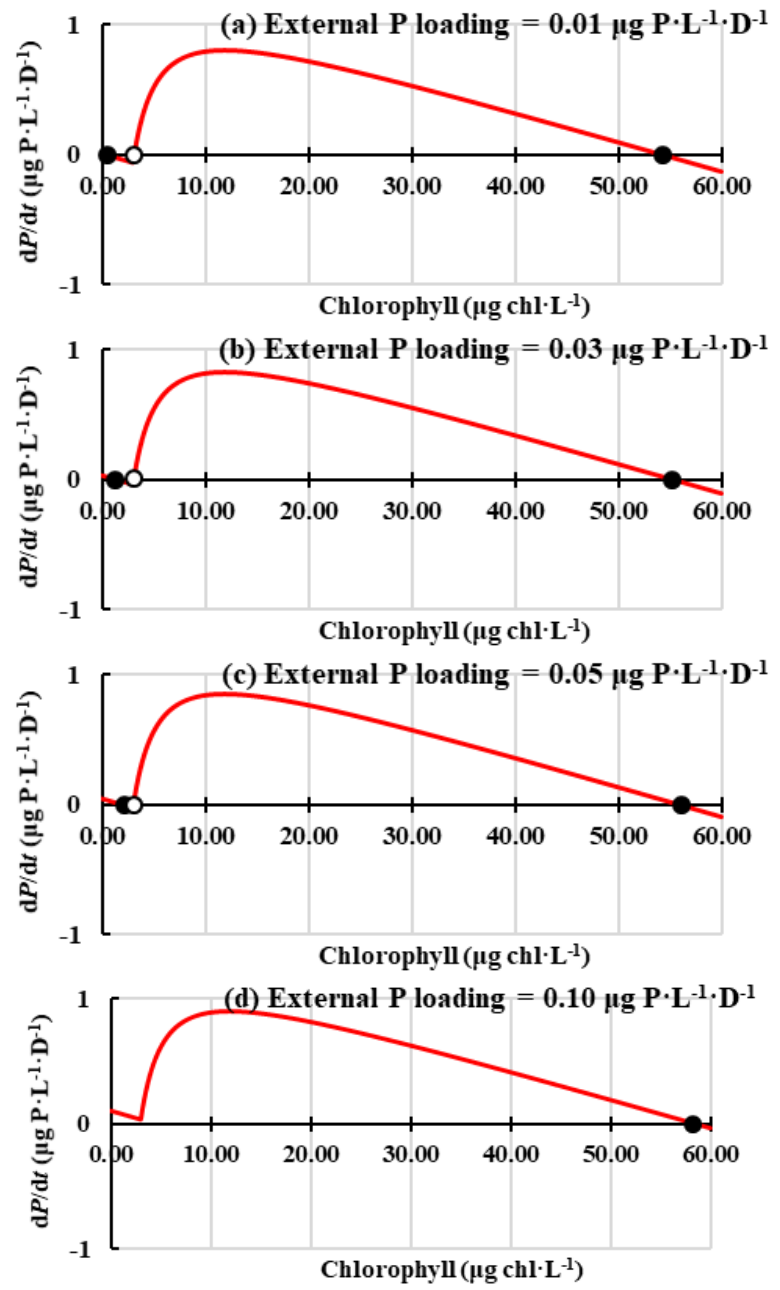

Fig. 2. Determination of $A^{*}$ (black circle is stable equilibrium and white circle is unstable equilibrium) with external $\mathrm{P}$ loading rates $l$ of (a) 0.01 , (b) 0.03 , (c) 0.05 and (d) $0.10 \mu \mathrm{g} \mathrm{P} \cdot \mathrm{L}^{-1} \cdot \mathrm{D}^{-1}$, for Sunway Lagoon.

Fig. 2 shows the simulation results for Sunway Lagoon under four scenarios of external $\mathrm{P}$ loading rate $l$ of $0.01,0.03$, 0.05 and $0.10 \mu \mathrm{g} \mathrm{P} \cdot \mathrm{L}^{-1} \cdot \mathrm{d}^{-1}$. In the case of three equilibria, the 
unstable equilibrium is in between two stable equilibria, one with low Chl-a concentration and one with high Chl-a concentration. Firstly, as observed in Fig. 2(a), when $l=0.01$ $\mu \mathrm{g} \mathrm{P} \cdot \mathrm{L}^{-1} \cdot \mathrm{D}^{-1}, \mathrm{~d} P / \mathrm{d} t$ changes sign three times at $A^{*}=0.43,3.13$ and $54.31 \mu \mathrm{g} \mathrm{Chl} \cdot \mathrm{L}^{-1}$, yielding two stable equilibria $(0.43$ and $\left.54.31 \mu \mathrm{g} \mathrm{Chl} \cdot \mathrm{L}^{-1}\right)$ and one unstable equilibrium $(3.13 \mu \mathrm{g}$ $\left.\mathrm{Chl} \cdot \mathrm{L}^{-1}\right)$. This means that if the concentration of Chl-a is close to $3.13 \mu \mathrm{g} \mathrm{Chl} \cdot \mathrm{L}^{-1}$, then it may shift abruptly to a eutrophic regime and stay stable at $A^{*}=54.31 \mu \mathrm{g} \mathrm{Chl} \cdot \mathrm{L}^{-1}$. Secondly, as observed in Fig. 2(c), as external $\mathrm{P}$ loading rate increases, the curve of $\mathrm{d} P / \mathrm{d} t$ shifts upwards, thereby shifting the oligotrophic stable equilibrium $\left(2.15 \mu \mathrm{g} \mathrm{Chl} \cdot \mathrm{L}^{-1}\right)$ closer to the unstable equilibrium $\left(3.05 \mu \mathrm{g} \mathrm{Chl} \cdot \mathrm{L}^{-1}\right)$. This means that an increase in external $\mathrm{P}$ loading rate may further increase the chances of regime shift. Thirdly, when $l=0.10 \mu \mathrm{g} \mathrm{P} \cdot \mathrm{L}^{-1} \cdot \mathrm{D}^{-1}$, $\mathrm{d} P / \mathrm{d} t$ changes sign once at $A^{*}=58.29 \mu \mathrm{g} \mathrm{Chl} \cdot \mathrm{L}^{-1}$ (Fig. $2(\mathrm{~d})$ ), yielding one stable eutrophic equilibrium. In this case, the concentration of Chl-a will likely converge to $58.29 \mu \mathrm{g}$ $\mathrm{Chl} \cdot \mathrm{L}^{-1}$, given the input of $l=0.10 \mu \mathrm{g} \mathrm{P} \cdot \mathrm{L}^{-1} \cdot \mathrm{D}^{-1}$.

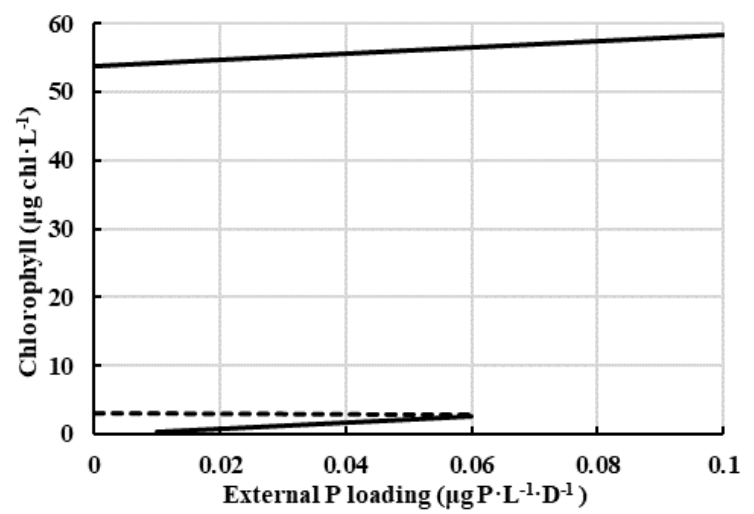

Fig. 3. Regime shift in Sunway Lagoon represented in a bifurcation figure, where solid line is stable equilibrium and dotted line is unstable equilibrium.
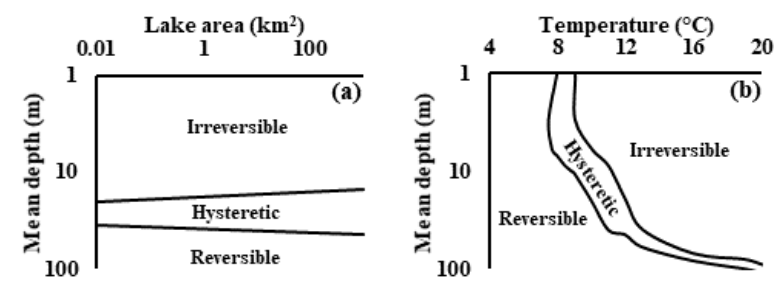

Fig. 4. Lake response types (reversible, hysteretic and irreversible) are affected by lake area, mean depth and temperature [20].

As observed in Fig. 3, three equilibria exist when external $P$ loading rate $l$ is between 0.01 and $0.06 \mu \mathrm{g} \mathrm{P} \cdot \mathrm{L}^{-1} \cdot \mathrm{D}^{-1}$. The vertical distance between the middle unstable equilibrium (dotted line) and the stable oligotrophic equilibrium (lower solid line) is a measure of resilience to eutrophication. The vertical distance between the middle unstable equilibrium (dotted line) and the eutrophic stable equilibrium (higher solid line) is a measure of resistance to restoration. As $l$ increases, the resilience to eutrophication of ecosystem decreases, while the resistance to restoration increases. High resistance to restoration means that restoration back to oligotrophic state will require more efforts and longer time even after the external $\mathrm{P}$ loading is reduced. Note that, the eutrophic stable equilibrium and unstable equilibrium are not continuous; indicating restoration to oligotrophic may not be possible for Sunway Lagoon. In other words, once shifted to eutrophic regime, Sunway Lagoon will be stable at eutrophic regime. In addition, shallow tropical lakes are typically irreversible, as displayed in Fig. 4. Sunway Lagoon has an area of $0.02 \mathrm{~km}^{2}$, mean depth of $8 \mathrm{~m}$ and temperature of $27^{\circ} \mathrm{C}$, falling into the irreversible lake response type in Fig. 4, indicating a high resistance to restoration.

\section{DISCUSSION}

Many lakes used for human water consumption worldwide, including Dianchi and Chaohu lakes, suffer from highly toxic cyanobacterial blooms. Regional climate change and human activities within watersheds exert a complex impact on aquatic ecosystem structures and functions across space and time. However, the degree to which these factors contribute to the long-term dynamics of plankton and other aquatic communities is not yet well understood. Recent modelling approaches attempt to grasp the non-linear processes involving multiple ecosystem components based upon limited ecological time series data in most lakes, with limited success. A minimalist approach [20] is undertaken in this paper to attempt to explain and predict future evolution in lake water quality in Sunway Lagoon. Attempting to overcome data paucity, other approaches have been suggested, including one that uses multi-proxy paleolimnological records to extract long-term ecological series data, and determine the inflection points of regime shifts in the Baiyangdian Lake, northern China [30]. Their research shows that the most important abrupt signals of ecological changes in the Baiyangdian Lake occurred in the early 1960s, a decade before the actual regime shift. They noted the rising variance, coupled with decreasing autocorrelation and skewness, started one decade before the regime shift, a phenomenon that has been observed elsewhere [23]. This ability to predict regime shifts early might provide time to prepare for appropriate remediation measures. The detection of regime shift early before its occurrence can provide valuable information and insights for lake management and aquatic ecosystem conservation. This detection might be achieved via three approaches [23]: (a) observation of early warning signals from multiple high resolution long-term time series or (b) model simulations utilizing limited site-specific data augmented by cross sectorial studies or (c) a combination of both. This paper adopts approach (b) to analyze regime shift and propose remediation measures for Sunway Lagoon, to be discussed in the conclusion section. We further review briefly the results of two regime shift research to provide additional insights and knowledge.

Located in the west of Hangzhou City, Zhejiang province, China, West Lake has an area of $6.5 \mathrm{~km}^{2}$ and a mean depth of $2.27 \mathrm{~m}$, giving a water volume of $1.49 \times 10^{7} \mathrm{~m}^{3}$. Outbreak of algae blooms and ecosystem degradation caused by the eutrophication occurred frequently in the West Lake since the 1950s. Abundant external nutrients originating from industrial and domestic wastewater, agricultural activities in the basin coupled with precipitation [31], [32], are the important contributors to algal blooms [33]. Submerged macrophyte restoration was successfully adopted to mitigate eutrophication and improve aquatic ecosystem in the West Lake [32]. After macrophyte restoration, macrophyte biomass 
and coverage were at a very high level, while nutrient levels and phytoplankton concentration significantly decreased. The decrease in nutrients is mainly attributed to the direct absorption by, and indirect release inhibition from, restored macrophytes. The reduction in phytoplankton might be the result of the growth inhibition due to decreased nutrients available for phytoplankton growth. Zooplankton, especially large-sized species, significantly increases after restoration, helping to graze down phytoplankton populations. The effective protections of zooplankton against fish predation provided by restored macrophytes might be the main reason for zooplankton increase. For the shallow West Lake, macrophyte restoration is an effective method to mitigate eutrophication and improve water quality, deserving the attentions of lake managements [32]. However, it remains an open question if microphyte restoration is effective for Sunway Lagoon, as the lake is deep at $8 \mathrm{~m}$ relative to its small surface area of 5 acres, providing limited littoral zones for microphytes restoration.

A six-year study was conducted to explore the impacts of multiple disturbance events (human resettlement, temperature change, rainfall, water level fluctuations) on phytoplankton and cyanobacteria dynamics in two subtropical reservoirs [34]. The Shidou and Bantou reservoirs are located in the headwater of Zhu River near Xiamen City, Fujian province, southeast China. The trophic states of these two reservoirs ranged from oligo-mesotrophic to eutrophic levels over time, an example of regime shift [35], [36]. The reservoirs provide critical ecological services including water supply to one million people in Xiamen City. Similar to Sunway Lagoon, these reservoirs have almost no macrophyte cover, having depths between 8 to $15 \mathrm{~m}$. Their research showed that combined multiple environmental disturbances triggered two apparent and abrupt regime shifts between cyanobacteria dominated state and non-cyanobacterial dominated state. In late 2010, the combined effect of human-resettlement (emigration) and natural disturbances (cooling, more rainfall, increase water level) led to a 60 to $90 \%$ decrease in cyanobacteria biomass. This was accompanied by the disappearance of cyanobacterial blooms, in tandem with an abrupt and persistent shift in phytoplankton community. After summer 2014, however, combined weather and hydrological disturbances (warming, less rainfall, lower water level) occurred, leading to an abrupt and significant increase in cyanobacteria biomass, associated with a return to cyanobacteria dominance. These changes in phytoplankton community were strongly related to the nutrient concentrations and water level fluctuations, as well as water temperature and rainfall. Sunway Lagoon might also be exposed to multiple disturbances, with consequences that are difficult to predict in advance. As extreme weather events and human disturbances are predicted to become more frequent and more severe during the twenty-first century, prudent sustainable lake management will require consideration of the background limnologic conditions and the frequency and severity of disturbance events when assessing the potential impacts on lake biodiversity and ecosystem functioning and services.

\section{CONCLUSION}

A minimalist model approach [20] is adopted in this paper to explain and predict regime shifts in Sunway Lagoon lake. The lake appears to have shifted from a mesotrophic state in 2010 to a eutrophic state in 2017. Given the status as an irreversible type of lake, and high temperature, intermediate water depth, inadequate flushing, unknown external $\mathrm{P}$ loadings and lack of littoral zones for microphytes restoration, it is likely that Sunway Lagoon would continue to progress towards a more severe form of eutrophication, if nothing is done to reduce external $\mathrm{P}$ input or increase flushing. The non-point sources of external P input cannot be controlled to reduce $\mathrm{P}$ loading rate $l$. However, nutrient rich lake water at a depth of $7.5 \mathrm{~m}$ can be regularly pumped off to effectively reduce the value of $l$, by increasing the flushing rate $h$ in (2). This nutrient rich water can be utilized as plant fertilizer. Further research will be pursued in the near future.

\section{REFERENCES}

[1] C. S. Holling, "Resilience and stability of ecological systems," Annual Review of Ecology and Systematics, vol. 4, pp. 1-23, 1973.

[2] M. Scheffer, S. Carpenter, J. A. Foley, C. Folke, and B. Walker, "Catastrophic shifts in ecosystems," Nature, vol. 413, pp. 591-596, 2001.

[3] M. Scheffer and S. R. Carpenter, "Catastrophic regime shifts in ecosystems: linking theory to observation," Trends in Ecology and Evolution, vol. 18, pp. 648-656, 2003.

[4] C. Huang, X. Wang, H. Yang, Y. Li, Y. Wang, X. Chen, and L. Xu, "Satellite data 9-15 regarding the eutrophication response to human activities in the plateau lake Dianchi in China from 1974 to 2009," Science of the Total Environment, vol. 485-486, pp. 1-11, 2014.

[5] X. Cao, Y. Wang, J. He, X. Luo, and Z. Zhang, "Phosphorus mobility among sediments, water and cyanobacteria enhanced by cyanobacteria blooms in eutrophic Lake Dianchi," Environmental Pollution, vol. 219, pp. 580-587, 2016.

[6] M. Li, G. Q. Xie, C. R. Dai, L. X. Yu, F. R. Li, and S. P. Yang, “A study of the relationship between the water body chlorophyll a and water quality factors of the offcoast of Dianchi Lake," Yunnan Geographic Environment Research, vol. 21, pp. 102-106, 2009.

[7] Y. K. Li, Y. Chen, B. Song, D. Olson, N. Yu, and L. Q. Chen, "Ecosystem structure and functioning of Lake Taihu (China) and the impacts of fishing," Fisheries Research, vol. 95, pp. 309-324, 2009.

[8] M. Coll, A. Santojanni, I. Palomera, S. Tudela, and E. Arneri, "An ecological model of the Northern and Central Adriatic Sea: Analysis of ecosystem structure and fishing impacts," Journal of Marine Systems, vol. 67, pp. 119-154, 2007.

[9] K. Shan, L. Li, X. Wang, Y. Wu, L. Hu, G. Yu, and L. Song, "Modelling ecosystem structure and trophic interactions in a typical cyanobacterial bloom-dominated shallow Lake Dianchi, China," Ecological Modelling, vol. 291, pp. 82-95, 2014.

[10] J. Lu, H. B. Wang, M. Pan, J. Xia, W. Xing, and G. H. Liu, "Using sediment seed banks and historical vegetation change data to develop restoration criteria for a eutrophic lake in China," Ecological Engineering, vol. 39, pp. 95-103, 2012.

[11] C. P. McDonald, N. R. Urban, and C. M. Casey, "Modeling historical trends in Lake Superior total nitrogen concentrations," Journal of Great Lakes Research, vol. 36, pp. 715-721, 2010.

[12] Q. Y. Tu, D. X. Gu, C. Q. Yi, Z. R. Xu, and G. Z. Han, The Researches on the Lake Chaohu Eutrophication, Hefei, China: Publisher of University of Science and Technology of China, 1990.

[13] X. Kong, L. Dong, W. He, Q. Wang, W. M. Mooij, and F. Xu, "Estimation of the long-term nutrient budget and thresholds of regime shift for a large shallow lake in China," Ecological Indicators, vol. 52, pp. 231-244, 2015.

[14] M. Sondergaard, J. P. Jensen, and E. Jeppesen, "Role of sediment and internal loading of phosphorus in shallow lakes," Hydrobiologia, vol. 506, pp. 135-145, 2003.

[15] L. Q. Xie, P. Xie, and H. J. Tang, "Enhancement of dissolved phosphorus release from sediment to lake water by Microcystis blooms - An enclosure experiment in a hyper-eutrophic, subtropical China lake," Environmental Pollution, vol. 122, pp. 391-399, 2003. 
[16] X. L. Bai, S. M. Ding, C. X. Fan, T. Liu, D. Shi, and L. Zhang, "Organic phosphorus species in surface sediments of a large, shallow, eutrophic lake, Lake Taihu, China," Environmental Pollution, vol. 157 pp. 2507-2513, 2009

[17] D. J. Conley, H. W. Paerl, R. W. Howarth, D. F. Boesch, S. P. Seitzinger, K. E. Havens, C. Lancelot, and G. E. Likens, "Controlling eutrophication: nitrogen and phosphorus," Ecology, vol. 323, pp. 1014-1015, 2009.

[18] J. G. Ferreira, J. H. Andersen, A. Borja, S. B. Bricker, J. Camp, M. Cardoso da Silvaf, E. Garcés, A.-S. Heiskanen, C. Humborg, L. Ignatiades, C. Lancelot, A. Menesguen, P. Tett, N. Hoepffner, and U. Claussen, "Overview of eutrophication indicators to assess environmental status within the European marine strategy framework directive," Estuaries, Coastal and Shelf Science, vol. 93, pp. 117-131, 2011.

[19] D. A. Lemley, J. B. Adams, S. Taljaard, and N. A. Strydom, "Towards the classification of eutrophic condition in estuaries," Estuaries, Coastal and Shelf Science, vol. 164, pp. 221-232, 2015.

[20] M. Genkai-Kato and S. R. Carpenter, "Eutrophication due to phosphorus recycling in relation to lake morphometry, temperature, and macrophytes," Ecology, vol. 86, pp. 210-219, 2005.

[21] S. Y. Teh, H. L. Koh, A. M. I. Izani, and M. Mansor, "Determining Photosynthesis Rate Constants in Lake Harapan Penang," in Proc. the First International Conference on Biomedical Engineering and Informatics, pp. 585-590, 2008.

[22] P. D. N. Srinivasu, "Regime shifts in eutrophicated lakes: A mathematical study," Ecological Modelling, vol. 179, pp. 115-130, 2004.

[23] S. Carpenter and W. Brock, "Rising variance: A leading indicator of ecological transition," Ecology Letters, vol. 9, pp. 311-318, 2006

[24] M. Scheffer, Ecology of Shallow Lakes, New York, U.S.A.: Chapman and Hall, 1998.

[25] W. E. Walker, M. Haasnoot, and J. H. Kwakkel, "Adapt or perish: A review of planning approaches for adaptation under deep uncertainty," Sustainability, vol. 5, pp. 955-979, 2013.

[26] P. Ashwin, S. Wieczorek, R. Vitolo, and P. Cox, "Tipping points in open systems: bifurcation, noise-induced and rate-dependent examples in the climate system," Philosophical Transactions of the Royal Society A, vol. 370, pp. 1166-1184, 2012.

[27] R. Singh, P. M. Reed, and K. Keller, "Many-objective robust decision making for managing an ecosystem with a deeply uncertain threshold response," Ecology and Society, vol. 20, pp. 12, 2015.

[28] M. N. Charlton, "Hypolimnion oxygen consumption in lakes: Discussion of productivity and morphometry effects," Canadian Journal of Fisheries and Aquatic Sciences, vol. 37, pp. 1531-1539, 1980.

[29] H. L. Koh, "Sunway Lagoon Rehabilitation Study: Data, Simulation and Synthesis," Report submitted to Sunway Lagoon Theme Park, Selangor Malaysia, 2017

[30] Y. Yang, X. Yin, Z. Yang, T. Sun, and C. Xu, "Detection of regime shifts in a shallow lake ecosystem based on multi-proxy paleolimnological indicators," Ecological Indicators, 2017.

[31] F. E. Wang, P. Tian, J. Yu, G. M. Lao, and T. C. Shi, "Variations in pollutant fluxes of rivers surrounding Taihu Lake in Zhejiang Province in 2008," Physics and Chemistry of the Earth, Parts A/B/C, vol. 36, pp 366-371, 2011.

[32] H. Zhang and G. H. Huang, "Assessment of non-point source pollution using as spatial multicriteria analysis approach," Ecological Modelling, vol. 222, pp. 313-321, 2011.

[33] I. A. Najar and A. B. Khan, "Assessment of water quality and identification of pollution sources of three lakes in Kashmir, India, using multivariate analysis," Environmental Earth Sciences, vol. 66, pp. 2367-2378, 2012.

[34] J. R. Yang, H. Lv, A. Isabwe, L. Liu, X. Yu, H. Chen, and J. Yang, "Disturbance-induced phytoplankton regime shifts and recovery of cyanobacteria dominance in two subtropical reservoirs," Water Reseach, vol. 120, pp. 52-63, 2017.
[35] J. Yang, H. Lv, J. Yang, L. Liu, X. Yu, and H. Chen, "Decline in water level boosts cyanobacteria dominance in subtropical reservoirs," Science of the Total Environment, vol. 557-558, pp. 445-452, 2016.

[36] H. Lv, J. Yang, L. Liu, X. Yu, Z. Yu, and P. Chiang, "Temperature and nutrients are significant drivers of seasonal shift in phytoplankton community from a drinking water reservoir, subtropical China," Environmental Science and Pollution Research, vol. 21, pp. 5917-5928, 2014.

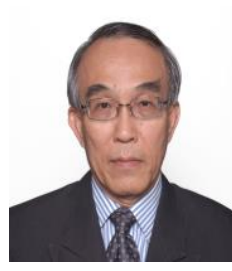

H. L. Koh was born on May 30, 1948 in Penang, Malaysia. He received his BSc from University of Malaya in 1970 and MA as well as $\mathrm{PhD}$ in mathematics in 1971 and 1976 respectively from University of Wisconsin, Madison, USA.

$\mathrm{He}$ was the recipient of Oppenheim Prize of University of Malaysia and Fulbright Scholarship USA and DAAD fellowship. He served as an associate member of the International Centre for Theoretical Physics (ICTP) from 1986 to 1992 . He is currently a Senior Fellow and Professor at the Jeffrey Sachs Center on Sustainable Development in Sunway University. He has served for 40 years in Universiti Sains Malaysia before continuing his research at Sunway University. His fields of specialization include environmental and ecological system modeling and simulations, integrated river basin management and modeling, numerical modeling of tsunami hazards and numerical simulation of dengue and H1N1 epidemics.

Prof. Koh has many journal publications, notably in Water Sciences \& Technology, Environmental Monitoring and Assessment, Water Quality Research Journal of Canada, Pollution in the Urban Environment, Journal of Asian Earth Sciences, Ecosystems, Ecological Modelling, Landscape Ecology and Agricultural and Forest Meteorology.

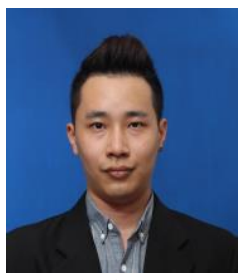

W. K. Tan was born in Pahang, Malaysia on Nov 6 , 1988. He received his $\mathrm{BSc}, \mathrm{MSc}$ and $\mathrm{PhD}$ in mathematical modeling in 2011, 2013 and 2017, respectively, all from Universiti Sains Malaysia.

Between 2014 and 2017, he was sponsored by the Abdus Salam International Centre for Theoretical Physics (ICTP), Vietnam Institute for Advanced Study in Mathematics (VIASM) and Institut Teknologi Bandung (ITB) to attend workshops related to mathematical modeling and high-performance computing. He is currently a Lecturer at School of Mathematical Sciences, Sunway University. His research interests include tsunami and aquatic ecosystem modeling and high-performance computing.

Dr. Tan has numerous publications indexed in ISI and Scopus.

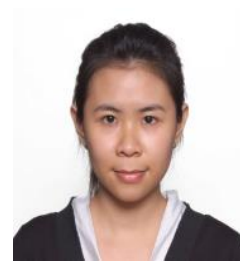

S. Y. Teh was born on Nov 5, 1981 in Kedah, Malaysia. She received her $\mathrm{BSc}, \mathrm{MSc}$ and $\mathrm{PhD}$ in mathematical modeling in 2004, 2005 and 2008 respectively, all from Universiti Sains Malaysia

In 2006, she was awarded the UNESCO/Keizo Obuchi Research Fellowship to undertake research on "Management Modeling of Everglades Wetlands Hydrology and Ecosystems" at University of Miami. Since then, she has been invited to University of Miami and Nanjing Forestry University under USGS grants and to four workshops at Abdus Salam International Centre for Theoretical Physics (ICTP) at Trieste, Italy under the sponsorship of ICTP. She is currently an Associate Professor at School of Mathematical Sciences, Universiti Sains Malaysia. She is the recipient of the prestigious L'Oréal-UNESCO National Women in Science Fellowship 2017. She works on various topics in ecosystem and environmental modeling, many of which were initiated and driven by the needs of the country or industry. Her research interests revolve around mathematical modeling with particular focus on computational simulation of real-life problems to provide insights and to suggest possible solutions.

Dr. Teh has many articles published in Journal of Asian Earth Sciences, Ecosystems, Ecological Modelling, Landscape Ecology and Agricultural and Forest Meteorology. 